\title{
Assessing record linkage between health care and Vital Statistics databases using deterministic methods Bing Li ${ }^{1}$, Hude Quan*1,2,3, Andrew Fong1 and Mingshan $\mathrm{Lu}^{1,3,4}$
}

\author{
Address: ${ }^{1}$ Department of Community Health Sciences, University of Calgary, Calgary, Alberta, T2N 4N1, Canada, ${ }^{2}$ Institute of Health Economics, \\ Edmonton, Alberta, T5J 3N4, Canada, ${ }^{3}$ Centre for Health and Policy Studies, University of Calgary, Calgary, Alberta, T2N 4N1, Canada and \\ ${ }^{4}$ Department of Economics, University of Calgary, Calgary, Alberta, T2N 1N4, Canada \\ Email: Bing Li - LIB@UCALGARY.CA; Hude Quan* - hquan@ucalgary.ca; Andrew Fong - andrew.fong@calgaryhealthregion.ca; \\ Mingshan Lu - lu@ucalgary.ca \\ * Corresponding author
}

Published: 05 April 2006

BMC Health Services Research 2006, 6:48 doi:10.1186/1472-6963-6-48

This article is available from: http://www.biomedcentral.com/l472-6963/6/48

(c) $2006 \mathrm{Li}$ et al; licensee BioMed Central Ltd.

This is an Open Access article distributed under the terms of the Creative Commons Attribution License (http://creativecommons.org/licenses/by/2.0), which permits unrestricted use, distribution, and reproduction in any medium, provided the original work is properly cited.

\begin{abstract}
Background: We assessed the linkage and correct linkage rate using deterministic record linkage among three commonly used Canadian databases, namely, the population registry, hospital discharge data and Vital Statistics registry.
\end{abstract}

Methods: Three combinations of four personal identifiers (surname, first name, sex and date of birth) were used to determine the optimal combination. The correct linkage rate was assessed using a unique personal health number available in all three databases.

Results: Among the three combinations, the combination of surname, sex, and date of birth had

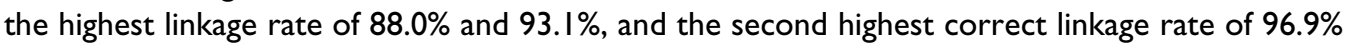
and $98.9 \%$ between the population registry and Vital Statistics registry, and between the hospital discharge data and Vital Statistics registry in 200I, respectively. Adding the first name to the combination of the three identifiers above increased correct linkage by less than $1 \%$, but at the cost of lowering the linkage rate almost by $10 \%$.

Conclusion: Our findings suggest that the combination of surname, sex and date of birth appears to be optimal using deterministic linkage. The linkage and correct linkage rates appear to vary by age and the type of database, but not by sex.

\section{Background}

Record linkage techniques are used widely in epidemiological studies to obtain comprehensive information and conduct more robust analyses [1-13]. For any record linkage project, two questions must be answered: 1) What is the best way to achieve a high linkage rate in a cost-effective manner? 2) What is the correct linkage rate among the records that are linked?
The evolution from manual to computerized record linkage has helped to answer the first question. There are two commonly used computerized record linkage approaches: deterministic and probabilistic $[8,9]$. The deterministic record linkage approach generates links on the basis of a full agreement of a unique identifier or a set of common identifiers. This method minimizes the uncertainties in the match between two databases since only a complete match on a set of personal variables is accepted at the cost of lowering the linkage rate. The probabilistic record link- 
age approach creates links between two databases based on a calculated statistical probability of a set of common identifiers. The probability is used to determine whether a pair of records approximately refers to the same individual. Thus, probabilistic linkage maximizes linkage theoretically but may result in uncertainty for some potential links. For the second question, correct linkage depends on the amount of personal identifying information available on the records being linked. [6] When enough information is available to use deterministic record linkage, this method should increase the correct linkage with little sacrifice in lowering the linkage rate. On the other hand, when unique personal identifiers (such as social insurance number or personal health number) are not available, the linkage and correct linkage rates depend heavily on the uniqueness of a set of proxies (such as name, sex and date of birth).

Using both deterministic and probabilistic linkage approaches, Roos, Wajda and Nicol [8] assessed the linkage rate between Manitoba Health Services Commission and Canadian Vital Statistics data to verify Manitoba deaths aged 25 or older during 1970 and 1979. The deterministic linkage approach was first used to link the records in the two databases using eight personal identifiers (i.e. sex, death year, death month, death day, birth year, birth month, initial and location). Then, the probabilistic record linkage approach was used to further match the remaining unlinked records after deterministic linkage in these two databases. The linkage rate increased from $80.7 \%$ in 1970 to $95.8 \%$ in 1979 . Roos and Wajda [9] repeated the linkage assessment but used specific weights model methodology. The model was based on weights for eight personal identifiers (i.e., sex, death month, death day, birth year, birth month, location, initial and marital status). A numerical weight for each variable was calculated by logarithm of agreement or disagreement frequency in linked pairs divided by that in unlinked pairs. They found that with the improvement in data quality, the record linkage rate improved significantly. The deterministic linkage approach matched $98.6 \%$ of Vital Statistics records with 1987 Manitoba Health Services Commission data in contrast to $93.7 \%$ for 1973 data. Neither study took surname as an identifying variable because researchers did not have access to individual or family names.

In our study, we selected four common identifiers (surname, first name, sex, and date of birth) from a set of personal identifiers and composed three different combinations of four identifiers: (1) a combination of surname, sex and date of birth, (2) first name, sex, and date of birth, and (3) surname, first name, sex and date of birth. Then we assessed the deterministic linkage between the Vital Statistics registry and the population registry in one scenario, and between the Vital Statistics registry and the in-hospital death records in hospital discharge data in the second scenario for the fiscal years 1998/99 through 2001/02 for each combination. We assessed these three databases because they are widely used in population and health services research to determine death status, cause of death and medical history.

\section{Methods \\ Databases}

Three administrative health databases were employed. We restricted our study population to residents of Calgary Health Region (CHR), Alberta, Canada during fiscal years $1998 / 99$ through 2001/02. As of March 2002, CHR's population was approximately 1.1 million. Infants less than one year were excluded because of missing or inaccurate variables such as name. In Vital Statistics individuals were defined as CHR residents based on Standard Geographical Classification (SGC) for assessment of the linkage between Vital Statistics and the population registry. The SGC was used to classify residential areas based address or community [14]. Of 21679 deaths occurred in the CHR during $1998 / 99$ to $2001 / 2002$, 99 were excluded due to unknown SGC, 1358 were also excluded because of nonCHR residents, and 20222 were finally analyzed. Residential postal codes recorded in the hospital discharge data were used to define CHR residents for assessment of the linkage between Vital Statistics and hospital discharge data.

The first database was the Alberta Health Care Insurance Plan Registry (it was also called the population registry) for the CHR for the fiscal years 1998/1999 to 2001/2002. This registry contained demographic information of health care recipients. Canada has a government-financed universal health insurance system. All permanent residents are covered by the provincial health insurance plan except for Registered First Nations, prison inmates, and members of the military and the Royal Canadian Mounted Police all of which are the responsibility of the federal government. All eligible Alberta residents are assigned a unique lifetime Personal Health Number (PHN). Therefore, PHN is an ideal variable for performing record linkage. The Alberta insurance registry is nearly complete and consistent, and is used as a proxy for the population of Alberta.

The second database was the Alberta Vital Statistics registry for fiscal years $1998 / 99$ to $2001 / 2002$. Information in the death registry was derived from the Death Registration form, medical certificate of death, and the medical examiner's certificate of death (where appropriate). The registry captured deaths that occurred within Alberta but misses Alberta residents who died out of Alberta. Provincial and territorial Vital Statistics registries on all deaths were submitted to Statistics Canada annually. 
The third database was the hospital discharge abstracts for the fiscal years 1998/1999 to 2001/2002. Abstracts are filed for all inpatient discharges from all hospitals in the CHR. Professional coders reviewed inpatient charts and extracted data on PHN, demographics, diagnoses, procedures, physician specialty and status of alive or death.

\section{Common identifiers among three databases}

We selected surname, first name, sex, and date of birth as our common identifiers because they were less likely to be changed over time, compared to other identifiers like address. We assessed three different combinations of four identifiers: (1) surname (i.e. surname at birth or marital surname as recorded in these three databases), sex and date of birth (i.e. month, day, and year of birth); (2) first name, sex, and date of birth; (3) surname, first name, sex and date of birth.

To perform record linkage, the common identifiers were formatted in the same way across the three databases, capitalizing letters, removing blanks and dashes. One common linkage problem with using the name variable as a common identifier was that an individual's name could be represented in many different ways, with alternate spellings, initials, abbreviations and shortened forms of names making the linkage difficult. To deal with this common linkage issue, a Soundex coding method was employed to identify linkage between names that fail to match due to variant spellings of the names in the two databases [13]. The Soundex algorithm associated numbers with different groups of consonants, producing a numeric code following the initial letter that was robust with respect to variations in names that sound alike.

Correct linkage among the linked records was assessed by checking whether the unique PHN from various sources was identical within the matched record. We excluded matched records without PHN in both files. Although this identifier is complete both in the hospital discharge data and population registry, only $70 \%$ of the records in the Vital Statistics registry had a valid PHN, because it was not a mandatory variable.

\section{Deterministic record linkage}

Record linkage and correct linkage evaluation between vital statistics and population registry

We linked the Vital Statistics registry with the population registry three times, using each of the three approaches (see Figure 1). In the process of linkage, the Vital Statistics registry was used as the master. The linkage rate between the population registry and Vital Statistics files was calculated using the number of records in the Vital Statistics registry file as the denominator ( $\mathrm{N}$ in Figure 1 ) and the number of linked records as numerator ( $\mathrm{n}$ in Figure 1 ). In the process of linkage, about $2 \%$ of Vital Statistics records were matched with more than one population registry record (i.e., duplicate records) for approach one, about $6 \%$ for approach two and less than $0.1 \%$ for approach three.

To assess the correct linkage, we checked whether the PHN obtained from the population registry was identical to the PHN recorded in the Vital Statistics registry among the linked records. Specifically we restricted the linked records to those with a valid PHN and checked the proportion of these records where the Vital-PHN matched the population-PHN. The Vital Statistics records with duplicate population registry records no matter whether there were PHNs or not, were defined as incorrect links. The correct linkage rate was calculated using the ratio of linked records with the matched PHNs over those with a valid Vital-PHN (i.e. the ratio of $n_{b}$ over $n_{a}$ in the Figure 1 ).

Record linkage and correct linkage evaluation between in-hospital death records and vital statistics files

We first selected inhospital death records in the hospital discharge data. Because our version of hospital discharge data did not contain names, we linked them with the population registry using PHNs that were present for all records in both files to retrieve the surname and first name from the population registry. In the matching process, the in-hospital death records were accepted as the master. We matched the in-hospital deaths to the Vital Statistics deaths using the three approaches, respectively (see Figure 2 ). The number of death records in the hospital discharge data ( $\mathrm{N}$ in Figure 2) was used as a denominator to calculate the linkage rate. Among the three approaches, less than $0.1 \%$ of in-hospital death records had more than one match with Vital Statistics files. Likewise, those duplicate matches were defined as incorrect links. Correct linkage was assessed by checking whether the inhospital-PHN matched the Vital-PHN within the linked record. The correct linkage rate was obtained by the ratio of $n_{b}$ divided by $\mathrm{n}_{\mathrm{a}}$ (see Figure 2).

\section{Results \\ Linkage and correct linkage rates between vital statistics and population registry}

Table 1 presents the percentage of deaths in the Vital Statistics registry which can be linked with the population registry. Among the three approaches, approach one (surname, sex and date of birth) had the highest linkage rate (88.0\% in 2001/02) compared to approach two (first name, sex and date of birth, $82.4 \%$ in 2001/02) and approach three (surname, first name, sex and date of birth, $79.5 \%$ in 2001/02).

For all three approaches, the linkage rate was similar between male and female in each fiscal year, but increased with age. For example, using approach one, the linkage 
Common Identifiers

Combination1: Surname, Sex and Date of Birth

Combination2: First Name, Sex and Date of Birth

Combination3: Surname, First Name, Sex and

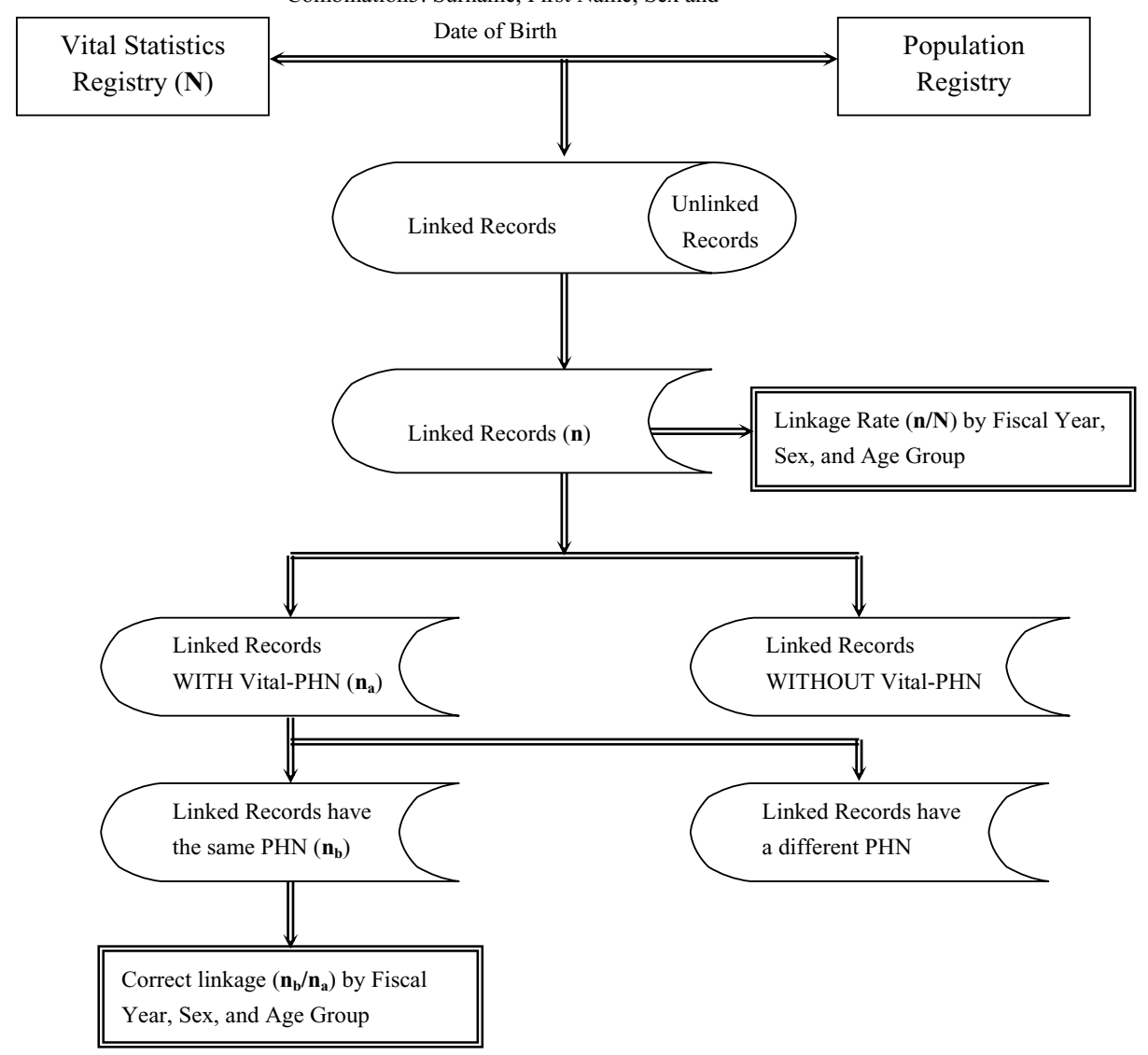

Figure I

Matching Process between Vital Statistics registry and Population registry. 


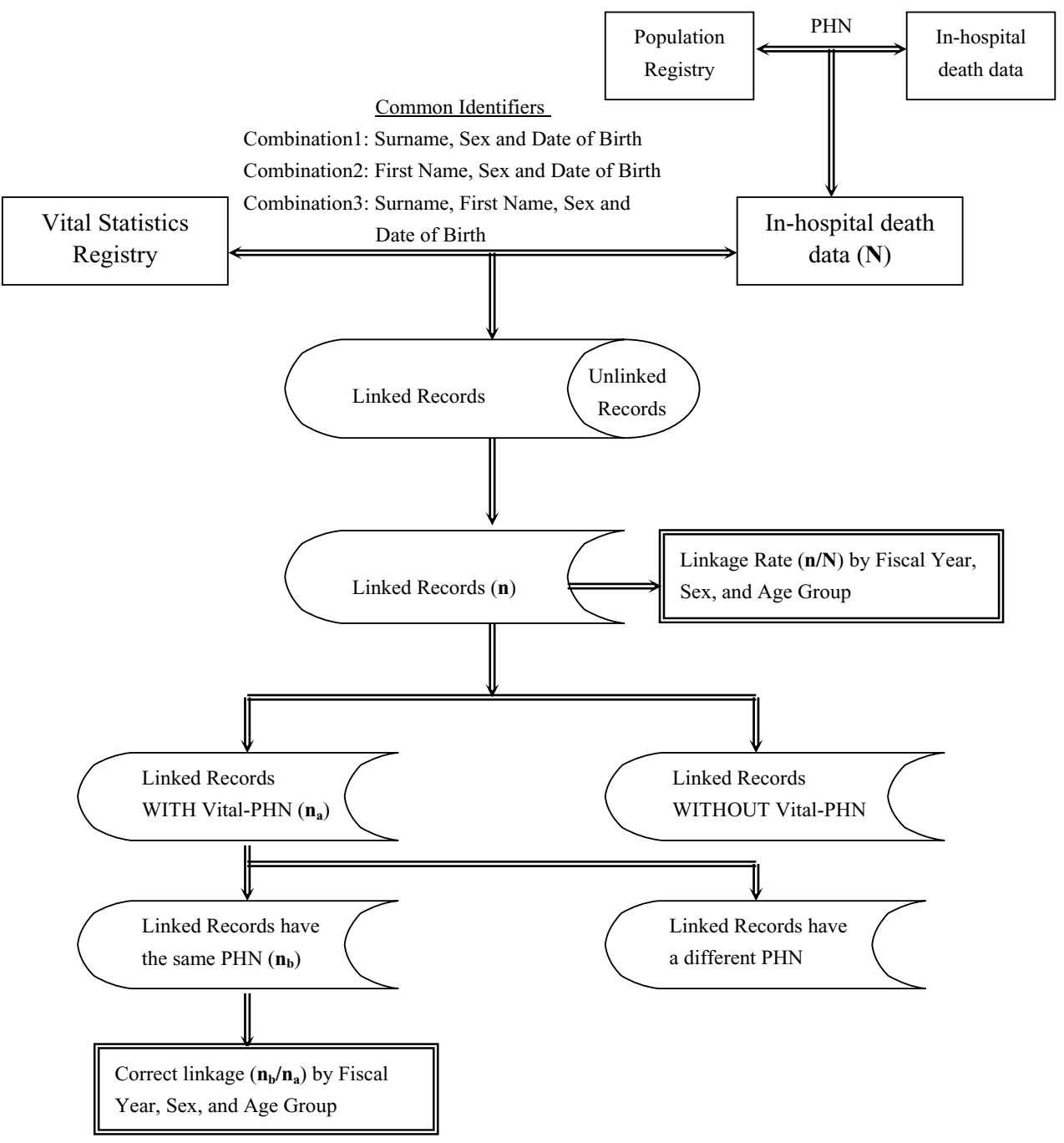

Figure 2

Matching Process between Vital Statistics registry and In-hospital death data. 
Table I: Linkage Rate (\%) between Vital Statistics registry and Population registry

\begin{tabular}{|c|c|c|c|c|c|}
\hline \multicolumn{2}{|c|}{ A combination of common identifiers } & $1998 / 99(N=4717)$ & $1999 / 00(N=5024)$ & $2000 / 01(N=5299)$ & $200 \mathrm{I} / 02(\mathrm{~N}=5 \mathrm{I} 82)$ \\
\hline \multicolumn{6}{|c|}{ Surname, Sex and Date of Birth } \\
\hline Total & & 85.6 & 85.6 & 87.2 & 88.0 \\
\hline \multirow[t]{2}{*}{ Sex: } & Female & 85.0 & 86.0 & 86.9 & 88.2 \\
\hline & Male & 86.2 & 85.3 & 87.5 & 87.7 \\
\hline \multirow{7}{*}{ Age: } & I to 9 years & 47.2 & 26.0 & 32.7 & 39.7 \\
\hline & 10 to 19 years & 70.5 & 77.8 & 67.4 & 66.7 \\
\hline & 20 to 29 years & 75.0 & 69.7 & 64.0 & 66.7 \\
\hline & 30 to 39 years & 86.4 & 80.1 & 80.9 & 82.8 \\
\hline & 40 to 49 years & 84.1 & 87.6 & 87.4 & 85.9 \\
\hline & 50 to 64 years & 83.2 & 85.6 & 87.2 & 88.0 \\
\hline & Over 65 years & 87.2 & 87.5 & 89.0 & 90.0 \\
\hline \multicolumn{6}{|c|}{ First Name, Sex and Date of Birth } \\
\hline Total & & 78.8 & 79.5 & 81.2 & 82.4 \\
\hline \multirow[t]{2}{*}{ Sex: } & Female & 76.6 & 78.0 & 80.1 & 81.7 \\
\hline & Male & 80.9 & 81.0 & 82.2 & 83.2 \\
\hline \multirow[t]{7}{*}{ Age: } & I to 9 years & 41.5 & 26.0 & 34.6 & 36.5 \\
\hline & 10 to 19 years & 59.1 & 68.9 & 61.2 & 50.0 \\
\hline & 20 to 29 years & 70.0 & 71.6 & 67.4 & 73.1 \\
\hline & 30 to 39 years & 87.6 & 80.1 & 77.8 & 79.1 \\
\hline & 40 to 49 years & 83.7 & 83.0 & 87.0 & 84.0 \\
\hline & 50 to 64 years & 76.8 & 81.2 & 82.4 & 83.4 \\
\hline & Over 65 years & 79.5 & 80.3 & 81.8 & 83.7 \\
\hline \multicolumn{6}{|c|}{ Surname, First Name, Sex and Date of Birth } \\
\hline Total & & 75.5 & 76.0 & 78.7 & 79.5 \\
\hline \multirow[t]{2}{*}{ Sex: } & Female & 73.0 & 74.5 & 77.1 & 78.9 \\
\hline & Male & 77.8 & 77.5 & 80.1 & 80.0 \\
\hline \multirow[t]{7}{*}{ Age: } & I to 9 years & 41.5 & 22.1 & 32.7 & 34.9 \\
\hline & 10 to 19 years & 52.3 & 60.0 & 51.0 & 47.0 \\
\hline & 20 to 29 years & 63.0 & 60.6 & 59.3 & 62.8 \\
\hline & 30 to 39 years & 79.9 & 73.3 & 71.6 & 71.6 \\
\hline & 40 to 49 years & 73.9 & 76.3 & 81.1 & 78.1 \\
\hline & 50 to 64 years & 72.2 & 76.9 & 78.8 & 79.4 \\
\hline & Over 65 years & 77.2 & 77.8 & 80.2 & 81.5 \\
\hline
\end{tabular}

rate was $39.7 \%$ for age 1 to 9 years and $90.0 \%$ for age 65 or older in fiscal year 2001/02. The linkage rate across fiscal years varied for age group of 1 to 39 years old and tended to increase for age groups of 40 years or older.

The correct linkage rate of record linkage among records that were linked between the Vital Statistics registry and population registry data for each approach is presented in Table 2. The correct linkage rate was $96.9 \%$ using approach one, $89.6 \%$ using approach two, and $98.5 \%$ using approach three in the 2001 fiscal year. The correct linkage rate showed an upward trend across fiscal years for all three approaches. The correct linkage rate was similar for both sex and age groups.

\section{Linkage and correct linkage rates between in-hospital} death records and vital statistics files

Table 3 shows that the record linkage rate between in-hospital death records and Vital Statistics in 2001/02 was 93.1\% using approach one, 85.0\% using approach two, and $83.3 \%$ using approach three. For each record linkage approach, the linkage rate increased over fiscal years, was slightly higher for males than females, and did not vary much by age. In 2001/02, approach one had the lowest linkage rate for the 20 to 29 year age group (70.0\%) but the highest rate for age 50 to 64 years $(94.7 \%)$.

Table 4 shows the correct linkage rate among those linked between hospital discharge data and the Vital Statistics registry after excluding $29 \%$ to $43 \%$ of Vital Statistics records because of missing PHN values. The correct linkage rate was similar across three approaches, 98.9\% using approach one in 2001/02, 98.8\% using approach two and $99.1 \%$ using approach three. The correct linkage rate increased each fiscal year but was stable across sex and age.

\section{Discussion}

This study assessed the record linkage and correct linkage rate using a deterministic record linkage method among three Canadian administrative databases. Our results showed that among the three combinations using the four 
Table 2: Correct Linkage Rates (\%) among Records Matched between Vital Statistics registry and Population registry

\begin{tabular}{|c|c|c|c|c|c|}
\hline \multicolumn{2}{|c|}{ A combination of common identifiers } & $1998 / 99$ & $1999 / 00$ & $2000 / 01$ & $2001 / 02$ \\
\hline \multicolumn{2}{|c|}{ Surname, Sex and Date of Birth } & $(N=2620)$ & $(N=30 \mid 4)$ & $(N=3445)$ & $(N=3530)$ \\
\hline \multicolumn{2}{|c|}{ Total } & 96.1 & 96.3 & 96.9 & 96.9 \\
\hline Sex: & Female & 96.4 & 96.2 & 97.2 & 97.3 \\
\hline \multirow[t]{8}{*}{ Age: } & Male & 95.8 & 96.4 & 96.5 & 96.6 \\
\hline & I to 9 years & 100.0 & 92.3 & 100.0 & 93.3 \\
\hline & 10 to 19 years & 86.7 & 94.7 & 100.0 & 96.0 \\
\hline & 20 to 29 years & 96.2 & 87.9 & 87.5 & 90.5 \\
\hline & 30 to 39 years & 90.9 & 92.4 & 90.8 & 94.8 \\
\hline & 40 to 49 years & 93.9 & 93.5 & 96.0 & 94.5 \\
\hline & 50 to 64 years & 93.8 & 95.9 & 94.5 & 96.0 \\
\hline & Over 65 years & 96.8 & 96.8 & 97.5 & 97.4 \\
\hline \multicolumn{2}{|c|}{ First Name, Sex and Date of Birth } & $(N=2405)$ & $(N=2777)$ & $(\mathrm{N}=3202)$ & $(N=3298)$ \\
\hline \multicolumn{2}{|c|}{ Total } & 89.3 & 89.1 & 89.3 & 89.6 \\
\hline \multirow[t]{2}{*}{ Sex: } & Female & 89.5 & 90.0 & 89.3 & 90.5 \\
\hline & Male & 89.1 & 88.1 & 89.3 & 88.7 \\
\hline \multirow[t]{7}{*}{ Age: } & I to 9 years & 100.0 & 91.7 & 70.0 & 85.7 \\
\hline & 10 to 19 years & 76.9 & 87.5 & 73.7 & 84.2 \\
\hline & 20 to 29 years & 91.7 & 80.0 & 86.4 & 76.0 \\
\hline & 30 to 39 years & 74.2 & 74.6 & 67.7 & 73.7 \\
\hline & 40 to 49 years & 71.7 & 66.4 & 68.2 & 71.6 \\
\hline & 50 to 64 years & 82.9 & 88.5 & 82.0 & 85.2 \\
\hline & Over 65 years & 91.9 & 91.9 & 92.8 & 92.2 \\
\hline \multicolumn{2}{|c|}{ Surname, First Name, Sex and Date of Birth } & $(N=23 I I)$ & $(N=2672)$ & $(N=3 \mid 20)$ & $(N=3188)$ \\
\hline \multicolumn{2}{|c|}{ Total } & 97.3 & 97.6 & 98.2 & 98.5 \\
\hline \multirow[t]{2}{*}{ Sex: } & Female & 97.6 & 97.8 & 98.1 & 98.3 \\
\hline & Male & 97.1 & 97.4 & 98.2 & 98.7 \\
\hline \multirow[t]{7}{*}{ Age: } & I to 9 years & 100.0 & 100.0 & 100.0 & 100.0 \\
\hline & 10 to 19 years & 91.7 & 100.0 & 100.0 & 94.1 \\
\hline & 20 to 29 years & 100.0 & 96.2 & 100.0 & 100.0 \\
\hline & 30 to 39 years & 96.6 & 98.3 & 96.7 & 98.2 \\
\hline & 40 to 49 years & 95.8 & 96.3 & 99.3 & 98.2 \\
\hline & 50 to 64 years & 95.3 & 97.7 & 98.0 & 98.5 \\
\hline & Over 65 years & 97.8 & 97.6 & 98.1 & 98.5 \\
\hline
\end{tabular}

possible identifiers, the combination of surname, sex and date of birth is the optimal choice in achieving the best deterministic linkage. Adding first name to the combination of identifiers increased the correct linkage rate no more than $1 \%$, but at the cost of decreasing the linkage rate almost $10 \%$. The linkage rate between the population and Vital Statistics registries when using the combination of surname, sex and date of birth was $88.0 \%$; the correct linkage rate was $96.9 \%$. For linkage between in-hospital death data and the Vital Statistics registry, the same combination achieved a linkage rate of $93.1 \%$ and a correct linkage rate of $98.9 \%$. The linkage and correct linkage rates varied with the database being used and the age group, but not by sex.

The linkage and correct linkage rates depend on the databases being linked. The linkage between the population and Vital Statistics registries produced lower linkage and correct linkage rates than those between hospital dis- charge data and the Vital Statistics registry. One possible reason for this is that while completing death certificates for in-hospital deaths, hospital charts were consulted and personal information recorded in the chart was copied. Personal information in the chart is generally from the health insurance card, on which the Alberta health insurance plan prints PHN, full name, sex and date of birth. Thus more complete and accurate information might be included on death certificates for in-hospital deaths, thereby improving the linkage between Vital Statistics and hospital discharge data.

Vital Statistics records without PHN are likely to be persons who died out of hospital. Personal information for those deaths is from various sources, resulting in inconsistencies in personal information between Vital Statistics and the Alberta population registry. For persons who are not eligible for Alberta Health Insurance plan (such as inmates, travelers, visitors, expatriates, armed forces, and 
Table 3: Linkage Rates (\%) between Vital Statistics registry and In-hospital death data

\begin{tabular}{|c|c|c|c|c|c|}
\hline \multicolumn{2}{|c|}{ A combination of common identifiers } & $1998 / 99(N=1639)$ & $1999 / 00(N=1637)$ & $2000 / 0 I(N=1707)$ & $200 \mathrm{I} / 02(\mathrm{~N}=1779)$ \\
\hline \multicolumn{6}{|c|}{ Surname, Sex and Date of Birth } \\
\hline Total & & 89.6 & 89.3 & 91.5 & 93.1 \\
\hline \multirow[t]{2}{*}{ Sex: } & Female & 88.0 & 88.3 & 90.8 & 93.8 \\
\hline & Male & 90.9 & 90.1 & 92.0 & 92.4 \\
\hline \multirow[t]{7}{*}{ Age: } & I to 9 years & 100.0 & 100.0 & 88.9 & 77.8 \\
\hline & 10 to 19 years & 100.0 & 85.7 & 88.9 & 92.3 \\
\hline & 20 to 29 years & 88.2 & 80.0 & 78.6 & 70.0 \\
\hline & 30 to 39 years & 92.1 & 80.6 & 83.9 & 85.2 \\
\hline & 40 to 49 years & 87.7 & 90.1 & 90.7 & 88.2 \\
\hline & 50 to 64 years & 85.5 & 87.1 & 91.1 & 94.7 \\
\hline & Over 65 years & 90.2 & 90.0 & 91.9 & 93.5 \\
\hline \multicolumn{6}{|c|}{ First Name, Sex and Date of Birth } \\
\hline Total & & 80.1 & 82.3 & 82.8 & 85.0 \\
\hline \multirow[t]{2}{*}{ Sex: } & Female & 76.6 & 80.8 & 82.7 & 83.3 \\
\hline & Male & 83.2 & 83.6 & 82.9 & 86.6 \\
\hline \multirow[t]{7}{*}{ Age: } & I to 9 years & 77.8 & 83.3 & 100.0 & 88.9 \\
\hline & 10 to 19 years & 70.0 & 78.6 & 66.7 & 76.9 \\
\hline & 20 to 29 years & 94.1 & 70.0 & 78.6 & 80.0 \\
\hline & 30 to 39 years & 89.5 & 86.1 & 74.2 & 74.1 \\
\hline & 40 to 49 years & 80.3 & 79.0 & 84.0 & 83.9 \\
\hline & 50 to 64 years & 77.9 & 80.6 & 82.1 & 85.1 \\
\hline & Over 65 years & 80.2 & 82.9 & 83.1 & 85.4 \\
\hline \multicolumn{6}{|c|}{ Surname, First Name, Sex and Date of Birth } \\
\hline Total & & 78.2 & 79.8 & 81.7 & 83.3 \\
\hline \multirow[t]{2}{*}{ Sex: } & Female & 74.2 & 78.1 & 81.2 & 81.9 \\
\hline & Male & 81.6 & 81.4 & 82.2 & 84.5 \\
\hline \multirow[t]{7}{*}{ Age: } & I to 9 years & 77.8 & 83.3 & 88.9 & 77.8 \\
\hline & 10 to 19 years & 70.0 & 71.4 & 55.6 & 76.9 \\
\hline & 20 to 29 years & 88.2 & 60.0 & 78.6 & 60.0 \\
\hline & 30 to 39 years & 86.8 & 77.8 & 71.0 & 74.1 \\
\hline & 40 to 49 years & 76.5 & 77.8 & 80.0 & 81.7 \\
\hline & 50 to 64 years & 73.6 & 77.6 & 81.3 & 83.7 \\
\hline & Over 65 years & 78.8 & 80.8 & 82.3 & 83.7 \\
\hline
\end{tabular}

Royal Canadian Mounted Police), their PHNs would not be recorded in the Vital Statistics if they died in Alberta. However, such cases account for a small proportion of all deaths in Alberta.

The linkage rates between the Vital Statistics registry and hospital death do not vary much by age, but the linkage rate between the population registry and the Vital Statistics registry depends on age group. The linkage rate was significantly lower for the 1 to 9 year age group (ranging from $34.9 \%$ to $39.7 \%$ in $2001 / 02$ ) than for 10 and over year age group (ranging from $47.0 \%$ to $90.0 \%$ in 2001 / 02 ). The difference in linkage rates may reflect less accurate information recorded for out-of-hospital deaths in younger persons. Records with the PHN may have more complete and accurate information on common identifiers than those without the PHN. In fact, we found the linkage rate between the population registry and Vital Statistics was higher for Vital Statistics records with PHN than for records without PHN (89.5\% versus $81.0 \%$ in 2001/
2002). There were more PHNs missing for children aged 1 to 9 years $(42.9 \%$ in $2001 / 2002)$ than for individuals aged 10 or older (13.8\% in 2001/02).

A successful deterministic linkage relies not only on the completeness of data, but also on choosing an appropriate combination of common identifiers. In our study, a combination of surname, sex and date of birth has the highest linkage rate and second highest correct linkage rate. The combination of first name, sex and date of birth generated relatively low linkage and correct linkage rates. The combination of all four identifiers (first, surname, sex and date of birth) resulted in an even lower linkage rate with little increase in the correct linkage rate. One possibility is that alternate spellings, initials, abbreviations and shortened forms of first names are common in the database. Therefore we recommend the use surname, sex and date of birth as common identifiers in linking databases deterministically when a unique identifier is not available. 
Table 4: Correct linkage Rates (\%) among Matched Records between Vital Statistics registry and In-hospital death data

\begin{tabular}{|c|c|c|c|c|c|}
\hline \multicolumn{2}{|c|}{ A combination of common identifiers } & $1998 / 99$ & $1999 / 00$ & $2000 / 01$ & $2001 / 02$ \\
\hline \multicolumn{2}{|c|}{ Surname, Sex and Date of Birth } & $(N=1056)$ & $(N=1102)$ & $(N=1253)$ & $(N=|4| \mid)$ \\
\hline \multicolumn{2}{|c|}{ Total } & 98.1 & 97.1 & 98.7 & 98.9 \\
\hline \multirow[t]{2}{*}{ Sex: } & Female & 98.4 & 96.7 & 98.8 & 98.7 \\
\hline & Male & 97.9 & 97.4 & 98.6 & 99.2 \\
\hline \multirow[t]{7}{*}{ Age: } & I to 9 years & 100.0 & 100.0 & 100.0 & 100.0 \\
\hline & 10 to 19 years & 100.0 & 88.9 & 100.0 & 85.7 \\
\hline & 20 to 29 years & 100.0 & 90.9 & 100.0 & 100.0 \\
\hline & 30 to 39 years & 100.0 & 95.0 & 94.4 & 100.0 \\
\hline & 40 to 49 years & 96.3 & 98.3 & 98.1 & 100.0 \\
\hline & 50 to 64 years & 95.9 & 97.3 & 99.5 & 98.7 \\
\hline & Over 65 years & 98.5 & 97.2 & 98.7 & 99.0 \\
\hline \multicolumn{2}{|c|}{ First Name, Sex and Date of Birth } & $(\mathrm{N}=960)$ & $(N=1019)$ & $(N=1 \mid 42)$ & $(N=1286)$ \\
\hline \multicolumn{2}{|c|}{ Total } & 97.8 & 96.8 & 98.4 & 98.8 \\
\hline \multirow[t]{2}{*}{ Sex: } & Female & 98.1 & 96.3 & 98.7 & 98.7 \\
\hline & Male & 97.6 & 97.2 & 98.2 & 98.9 \\
\hline \multirow[t]{7}{*}{ Age: } & I to 9 years & 100.0 & 100.0 & 100.0 & 100.0 \\
\hline & 10 to 19 years & 100.0 & 88.9 & 75.0 & 80.0 \\
\hline & 20 to 29 years & 100.0 & 88.9 & 100.0 & 100.0 \\
\hline & 30 to 39 years & 100.0 & 95.0 & 94.4 & 100.0 \\
\hline & 40 to 49 years & 95.9 & 97.9 & 97.9 & 100.0 \\
\hline & 50 to 64 years & 95.6 & 97.1 & 98.8 & 98.6 \\
\hline & Over 65 years & 98.2 & 96.8 & 98.5 & 98.8 \\
\hline \multicolumn{2}{|c|}{ Surname, First Name, Sex and Date of Birth } & $(\mathrm{N}=936)$ & $(\mathrm{N}=990)$ & $(N=1126)$ & $(N=|26|)$ \\
\hline Total & & 97.9 & 96.8 & 98.7 & 99.1 \\
\hline \multirow[t]{2}{*}{ Sex: } & Female & 98.1 & 96.3 & 98.9 & 98.8 \\
\hline & Male & 97.7 & 97.2 & 98.5 & 99.3 \\
\hline \multirow[t]{7}{*}{ Age: } & I to 9 years & 100.0 & 100.0 & 100.0 & 100.0 \\
\hline & 10 to 19 years & 100.0 & 87.5 & 100.0 & 80.0 \\
\hline & 20 to 29 years & 100.0 & 87.5 & 100.0 & 100.0 \\
\hline & 30 to 39 years & 100.0 & 94.7 & 94.1 & 100.0 \\
\hline & 40 to 49 years & 95.8 & 97.9 & 97.8 & 100.0 \\
\hline & 50 to 64 years & 95.4 & 97.0 & 99.4 & 98.5 \\
\hline & Over 65 years & 98.3 & 96.9 & 98.6 & 99.2 \\
\hline
\end{tabular}

To further improve correct record linkage, other potential indicators, such as residence address or postal code, should be considered. In our study, only $67 \%$ to $77 \%$ of records in the Vital Statistics registry during 1998 and 2001 contained information on the unique identifier of personal health number, while $84 \%$ to $96 \%$ had information on postal codes. The linkage rates might be increased taking the strategy of first matching records using unique identifiers, and then matching remaining records using a combination of surname, sex and date of birth.

This study has four major limitations. First, we assessed record linkage using administrative databases in a Canadian health region. The results might not be conceptually generalizable to other Canadian regions or other countries because the quality of administrative data may vary across geographical areas and institutions. Secondly, records without PHN may have less complete and accurate information on common identifiers than those with
PHN. Therefore the higher the rate of missing PHNs is, the more likely the linkage rate is to be lower. We selected linked records with PHNs only to assess correct linkage rate. The potential selection bias may cause the correct linkage rate to be overestimated, particularly for children aged 1 to 9 since they have more missing PHNs than those aged 10 or older in Vital Statistics data. Thirdly, we excluded deaths with unknown residence area information and missed residents of the region who died out of Alberta, possibly leading to overestimates of our linkage rate if personal information on these deaths was less complete than those we analyzed. Fourthly, our linkage rate may be applicable to linking nested databases; one database contains all records of other database. In our study, all Vital Statistics Registry records are expected to appear in the Population Registry, and all in-hospital death records are expected to be present in the Vital Statistics Registry. Correct linkage could be assessed by four measures: true-link, false-link, true-nonlink and false-nonlink. 
Assessment of these four types requires a unique identifier present in both databases to establish the "gold standard". Our study addressed one question: what is correct linkage rate among links through deterministic record linkage?

\section{Conclusion}

Our study findings suggest that deterministic record linkage using three basic indicators (i.e., surname, sex and date of birth) appears to generate the highest linkage rate among three commonly used databases in health service research, namely the population registry, hospital discharge data and the Vital Statistics registry. The matched records appear to be highly accurate. However, the linkage and correct linkage rates appear to be influenced by type of database and age, but not by sex.

\section{Competing interests}

The author(s) declare that they have no competing interests.

\section{Authors' contributions}

BL contributed to the study design, statistical analysis, interpretation and writing of the manuscript. HQ contributed to the study design, the interpretation, and writing of the manuscript. AF helped data-analysis and interpretation and editing and proving the manuscript. ML contributed to the data interpretation and writing of the manuscript.

\section{Acknowledgements}

The authors thank Carolyn De Coster, research assistant professor at the University of Calgary for revision of the manuscript. Hude Quan is supported by a Population Health Investigator Award from the Alberta Heritage Foundation for Medical Research, Edmonton, Alberta, Canada and by a New Investigator Award from the Canadian Institutes of Health Research.

\section{References}

I. Goldberg MS, Carpenter M, Thériault G, Fair M: The accuracy of ascertaining vital status in a historical cohort study of synthetic textiles workers using computerized record linkage to the Canadian Mortality Data Base. Can J Public Health 1993, 84:20I-4.

2. Herrchen B, Gould JB, Nesbitt TS: Vital statistics linked birth/ infant death and hospital discharge record linkage for epidemiological studies. Comput Biomed Res 1997, 30:290-305.

3. Howe GR: Use of computerized record linkage in cohort studies. Epidemiol Rev 1998, 20: I I2-2I.

4. Muse AG, Mikl J, Smith PF: Evaluating the quality of anonymous record linkage using deterministic procedures with the New York State AIDS registry and a hospital discharge file. Stat Med 1995, 14:499-509.

5. Newcombe HB, Kennedy JM, Axford SJ, James AP: Automatic linkage of vital records. Science 1959, 130:954-9.

6. Newcombe HB, Smith ME, Howe GR, Mingary J, Strugnell A, Abbatt JD: Reliability of computerized versus death searches in a study of the health of Eldorado uranium workers. Comput Biol Med 1983, 13:157.

7. Newman TB, Brown A, Easterling MJ: Obstacles and approaches to clinical database research: experience at the University of California, San Francisco. Proc Annu Symp Comput Appl Med Care 1994:568-72.
8. Roos LL Jr, Wajda A, Nicol JP: The art and science of record linkage: methods that work with few identifiers. Comput Biol Med 1986, 1 6:45-57.

9. Roos LL, Wajda A, Record linkage strategies: Part I: Estimating information and evaluating approaches. Methods Inf Med I99I, 30: $117-23$.

10. Kelman CW, Bass AJ, Holman CDJ: Research use of linked health data - a best practice protocol. Aust N Z J Pulic Health 2002, 26:25I-5.

II. Van den Brandt PA, Schouten LJ, Goldbohm RA, Dorant E, Hunen $\mathrm{PM}$ : Development of a record linkage protocol for use in the Dutch Cancer Registry for Epidemiological Research. Int J Epidemiol 1990, 19:553-8

12. Waien SA: Linking large administrative databases: a method for conducting emergency medical services cohort studies using existing data. Acad Emerg Med 1997, 4:1087-95.

13. Knuth D: The art of computer programming: sorting and searching, Reading Massachusetts: Addison-Wesley; 1973.

14. Statistics Canada: Standard Geographical Classification (SGC) 200 I. [http://www.statcan.ca/english/Subjects/Standard/sgc/200I/ 200I-sgc-index.htm]. accessed on November 07, 2005

\section{Pre-publication history}

The pre-publication history for this paper can be accessed here:

http://www.biomedcentral.com/1472-6963/6/48/prepub
Publish with Biomed Central and every scientist can read your work free of charge

"BioMed Central will be the most significant development for disseminating the results of biomedical research in our lifetime. "

Sir Paul Nurse, Cancer Research UK

Your research papers will be:

- available free of charge to the entire biomedical community

- peer reviewed and published immediately upon acceptance

- cited in PubMed and archived on PubMed Central

- yours - you keep the copyright
BioMedcentral 